\title{
Projetos de extensão fazendo a diferença na formação do profissional de educação física na Unioeste
}

\author{
Extension projects making a difference in the formation of \\ physical education profissionals at Unioeste \\ Ricardo Brandt, Alberto Saturno Madureira, Edilson Hobold \\ Universidade Estadual do Oeste do Paraná (Unioeste), Marechal Cândido Rondon/PR, Brasil
}

HISTÓRICO DO ARTIGO

Recebido: 01 fevereiro 2020

Revisado: 01 abril 2020

Aprovado: 09 abril 2020

\section{PALAVRAS-CHAVE:}

Extensão Universitária; Formação Profissional; Serviço de Saúde.

\section{KEYWORDS}

University Extension; Training Course; Health Service.

\section{RESUMO}

INTRODUÇÃO: O processo ensino-aprendizagem extrapola a sala de aula, sendo que a extensão universitária contribui de forma significativa nesse processo, melhorando a condição do egresso na atuação do profissional da Educação Física.

OBJETIVO: Este trabalho teve por objetivo apresentar o impacto na vida dos acadêmicos que além de participarem das aulas normais propostas na matriz curricular também se envolvem em projetos de extensão e o quanto estas atividades podem contribuir além de suas formaç̃̃es, mas com a melhora dos seus currículos.

MÉTODOS: Este estudo e um relato de experiência que envolve três projetos de extensão que são desenvolvidos no campus da Unioeste de Marechal Cândido Rondon, do curso de Educação Física Bacharelado.

RESULTADOS: Três projetos que atualmente existem no curso de Educação Física - Bacharelado na Universidade Estadual do Oeste do Paraná, se destacam entre tantos outros, por impactar de forma positiva na formação dos discentes além de proporcionar a comunidade exercícios de forma gratuita, para populações de diferentes idades, sendo eles o projeto Coração de Ouro, com prática de exercício físico para idosos, o projeto Unioeste Runners que oferece treinamento de corrida de rua para jovens, adultos e idosos e o Projeto Futuro do Judô, que oportuniza esta prática esportiva para crianças, adolescentes e jovens de instituições públicas do município de Marechal Cândido Rondon.

CONCLUSÃO: Evidencia-se neste trabalho a importância da participação em projetos de extensão no processo de formação universitária, proporcionando vivencias diferenciadas na vida profissional do egresso.

\section{ABSTRACT}

BACKGROUND: Teaching-learning process goes beyond the classroom, and university extension contributes significantly this process, improving the condition of graduates in the performance of Physical Education professionals.

OBJECTIVE: The aim of this study is to present the impact in lives of academics who, in addition to participating in the normal classes proposed in the curricular matrix, are also involved in extension projects and how much these activities can contribute beyond their training, but with the improvement of their resumes.

METHODS: This study is experience report that involves three extension projects that are developed on the Unioeste campus of Marechal Cândido Rondon, the Bacharelado Physical Education course.

RESULTS: Three projects that currently exist in the Bachelor's Degree in Physical Education at the State University of Western Paraná, stand out among many others, for having a positive impact on the training of students, in addition to providing the community with free exercise, for populations of different ages, being the Heart of Gold project, with physical exercise for the elderly, the Unioeste Runners project, which offers running training for young people, adults and the elderly, and the Future of Judo Project, which provides this sports practice for children, adolescents and young people from public institutions in the municipality of Marechal Cândido Rondon.

CONCLUSION: This paper highlights the importance of participate in extension projects on university education process, providing differentiated experiences for the egress of great relevance for the future professional. 


\section{INTRODUÇAO}

A história da educação física se confunde entre o primitivo e o moderno. Inicialmente, a atividade física própria para a manutenção da vida (correr, saltar, arremessar) passa por uma fase de elaboração de conceitos e informações que em determinado momento passa a se tornar uma disciplina. A partir de uma disciplina isolada, admite-se que vai adquirindo conhecimento e informações até chegar a algo que extrapola e sua conformação aglutina um corpo de conhecimento unindo várias áreas da educação e da saúde.

Conforme Inezil Pena Marinho (apud MELO, 2007) os primeiros esforços para a formação de profissionais em educação física, no Brasil, tiveram início por volta de 1902, no Batalhão de Caçadores, no Quartel da Luz, São Paulo. Com a chegada de militares do exército francês, membros de uma missão contratada pela Província, em 1909 é criada a Escola de Educação Física da Força Pública de São Paulo. O primeiro programa civil de um curso de Educação Física de que se tem notícia é o do curso da Escola de Educação Física do Estado de São Paulo, criado em 1931, mas que só começou a funcionar em 1934 (SOUZA NETO et al., 2004).

Cronologicamente optou-se por iniciar este tópico a partir do Parecer Nº. 894/1969 e da Resolução N 69/1969 que enfatizavam o conhecimento esportivo e a parte didática voltada para a formação do professor. Porém, devido às novas demandas do mercado de trabalho para a Educação Física fora do contexto escolar e pensar a Educação Física como um campo de conhecimento específico exigia uma proposta diferenciada. A resolução 03/87 possibilitou um novo olhar para o processo de preparação profissional em Educação Física além do escolar (ANTUNES, 2009).

É com a Resolução № 3/1987 que se passou a ter a formação do bacharel em Educação Física, que apesar de ser uma formação em nível superior não havia exigência de tal para o exercício profissional, ou seja, qualquer pessoa podia ministrar qualquer conteúdo, sem qualquer exigência de formação.

Assim, a Educação Física brasileira enquanto profissão foi reconhecida pela Lei № 9696/98 de primeiro de setembro de 1998. E, é seu Artigo $3^{\circ}$ que trata da competência profissional:

Compete ao Profissional de Educação Física coordenar, planejar, programar, supervisionar, dinamizar, dirigir, organizar, avaliar e executar trabalhos, programas, planos e projetos, bem como prestar serviços de auditoria, consultoria e assessoria, realizar treinamentos especializados, participar de equipes multidisciplinares e interdisciplinares e elaborar informes técnicos, científicos e pedagógicos, todos nas áreas de atividades físicas e do desporto.

Até a promulgação da referida Lei era comum a contratação de alunos, chamados estagiários para desenvolver as atividades autonomamente, ou seja, sem a presença de um profissional. Entretanto, com a criação do sistema CONFEF/ CREF o ato profissional foi regulamentado e uma das principais mudanças foi que para qualquer aluno de Educação Física - Bacharelado atuar fora das instituições de ensino superior terá, obrigatoriamente, que estar sob a supervisão direta de um responsável técnico, ou seja, um bacharel em Educação Física devidamente registrado no conselho de classe. A ver pela Lei № 9696/98. o leque de competência profissional é amplo assim como o campo de trabalho.

Em que pese o curso de Educação Física da Universidade Estadual do Oeste do Paraná - Unioeste, ter sido criado em março de 1984, passou por várias e significativas mudanças, buscando adequar-se às legislações vigentes, de modo que o atual Projeto Pedagógico apresenta os objetivos gerais e específicos do curso (UNIOESTE, 2018).

\section{Objetivos Gerais do Curso: O Curso de Graduação em Educação Física da Unioeste surge com o objetivo fundamental de preparar profissionais de Educação Física para atuar em academias, clubes, instituições municipais e estaduais e hotéis e como treinadores, instrutores, coordenadores, organizadores, monitores de atividades físicas e recreativas, etc., visando o desenvolvimento esportivo, saúde e qualidade de vida da população. Contudo, além destes objetivos gerais, podem ser explicitados outros.}

Objetivos Específicos: a) contribuir para a melhoria da qualidade do serviço prestado de Educação Física em espaços informais, nas instituições não-escolares municipais, estaduais e particulares de Marechal Cândido Rondon e Região; b) viabilizar a formação de um profissional de Educação Física que compreenda a importância desta área do conhecimento para o desenvolvimento humano e para formação da consciência de cidadania; c) proporcionar um processo de formação em que a dimensão teóricoprática seja entendida e vivenciada de modo articulado no conjunto das atividades a serem desenvolvidas; d) promover atividades acadêmicas diversas e práticas pedagógicas vivas que contribuam para a aproximação entre a instituição formadora e os sistemas externos de aplicação da atividade física relacionada à saúde e ao desempenho esportivo; e) formar profissionais para atuarem na área de rendimento e aptidão relacionada ao esporte e à saúde; f) elaborar e desenvolver propostas de treinamento para o alto rendimento das diversas modalidades da Educação Física, que possam ser aplicadas em cooperação com outras áreas do conhecimento. g) proporcionar conhecimentos e técnicas atualizadas no esporte que permitam atuação no campo não-formal, como municípios, condomínios, clubes, academias, departamentos, secretarias, ligas, federações, confederações, instituições de ensino e outros; h) promover a oportunidade de contribuir para a geração e transformação do conhecimento científico no esporte; i) formar profissionais para atuarem na área de saúde e qualidade de vida; j) incentivar o desenvolvimento de projetos de extensão na área do lazer, do treinamento, das atividades recreativas e para a saúde, em diferentes segmentos populacionais; $k$ ) proporcionar conhecimentos atualizados e contextualizados na saúde e qualidade de vida, que permitam atuação em programas direcionados à saúde na comunidade, em município, em academias, em clubes, em condomínios e em empresas; l) promover a oportunidade de contribuir para a geração e transformação do conhecimento científico no desenvolvimento de programas de saúde e qualidade de vida.

Neste contexto, verifica-se que o processo ensino-aprendizagem extrapola a sala de aula fazendo com que docentes e discentes se unam na busca de alternativas que visem maior apropriação do conhecimento e a colocação em prática das informações e técnicas repassadas.

A Universidade Estadual do Oeste do Paraná (Unioeste), possui cinco campus, a saber, Cascavel (inclusive a Reitoria), Toledo, Marechal Cândido Rondon, Foz do Iguaçu e Francisco Beltrão. Em sua estrutura pedagógica está alicerçada no tripé: ensino, pesquisa e extensão (Resolução N. 102/2016-CEPE, Art. 19 - pesquisa, e Art. 20 - extensão).

Conforme o Art. 20 a descrição da extensão deve atender aos modos de integração entre ensino e extensão e entre a graduação e extensão.

Por outro lado, há uma Resolução específica que trata da extensão que é a de $\mathrm{N}^{\circ}$. 236/2014-CEPE, de 13 de novembro de 2014. Aprova as "normas e procedimentos específicos para atividades de extensão", da Unioeste. E, já, em seu artigo primeiro descreve: "A extensão Universitária é o processo educativo, cultural e científico, que articula o Ensino e a Pesquisa de forma indissociável entre a Universidade e a sociedade".

A partir destes pressupostos o curso de Educação Física - Bacharelado vem desenvolvendo projetos de extensão, a 
maioria de curta duração em forma de semana acadêmica, cursos, e atividades pontuais. Entretanto, três projetos se destacam por se caracterizarem como permanentes, e é sobre eles que buscar-se-á descrever o impacto na vida acadêmica dos discentes que deles participam, sem ater-se com detalhes ao impacto social pelas atividades prestadas gratuitamente à comunidade.

\section{MÉTODOS}

Este estudo e um relato de experiência que envolve projetos de extensão vinculados ao curso de Educação Física - Bacharelado, sendo eles: Projeto Coração de Ouro, desde 2001, Projeto Unioeste Runners, desde 2016 e Projeto Futuro do Judô, desde 1998. As informações apresentadas neste manuscrito foram obtidas nos documentos oficiais como os projetos de extensão e relatórios que foram confeccionados ao longo dos anos de funcionamento dos projetos.

\section{RESULTADOS}

\section{Projeto Coração de Ouro}

Com relação ao Projeto Coração de Ouro, teve seu início em agosto de 2001 e encerrou em 2019, teve a coordenação do Prof. Dr. Alberto saturno Madureira. O objetivo desde então é atender pessoas a partir da terceira idade, 60 anos, conforme o Estatuto do Idoso (Lei $\mathrm{N}^{\circ}$. 10.741/2003), com atividades de ginástica, três vezes por semana com a duração de uma hora de atividade. Além das atividades de ginástica, são incluídas atividades recreacionais, festa junina e natalina. Quando possível o grupo, acompanhado dos acadêmicos realizam passeio e participação em eventos oportunizados pela própria instituição. 0 grupo se mantém com 25 pessoas. Há quem já participe há pelo menos 15 anos. Por ser um grupo com idade avançada há que se considerar a perda de alguns. Neste período já ocorreram 4 falecimentos por situações adversas às atividades propostas.

As disciplinas de biologia, anatomia, fisiologia, medidas e avaliação, cineantropometria, cuidados especiais, atividades de academia, treinamento esportivo são as dão sustentação ao corpo de conhecimentos dos alunos ao longo se suas formações e a participação do professor orientador é que auxilia a modular as atividades conforme a necessidade do grupo, de modo a assegurar exercício físico com a segurança necessária aos participantes.

Por meio deste projeto, os acadêmicos podem melhor assimilar a teoria ao colocarem em prática os aspectos de aplicação de anamnese, realização de medidas antropométricas, realização de testes motores, medição de pressão arterial e controle de frequência cardíaca e respiratória. A partir das informações coletadas, os acadêmicos passam a tabular os dados e na sequência desenvolvem na prática conhecimentos de estatística básica que permite aos mesmos a apresentação em eventos de natureza científica, bem como publicação de trabalhos.

A efetiva participação dos acadêmicos no Seminário de Extensão da Unioeste, já selecionou este projeto 3 vezes para participar nas edições do Seminário de Extensão da Região Sul
(SEUR). Este projeto contou com alguns assessores voluntários e consultores técnicos: Samuel Assis Nascimento (médico); Gilberto Daniel Oswald (fisioterapeuta); Janete Maragno Madureira (psicóloga), Leodir José Pasetti (bioquímico, saiu 12/2003), Maria Salete Mota (nutricionista, saiu em 12/2002). Nos anos de 2001 a 2003 contou-se com aproximadamente 10 acadêmicos cujos dados se perderam em função de ainda não haver o registro dos mesmos via projeto; em 2004 contou com 9 acadêmicos; em 2005 com 12; 2006 com três; 2007 com quatro; 2008 com cinco; 2009 com quatro; 2010 com quatro; 2011 com dois; 2012 com um; 2013 com um; 2014 com dois; 2015 com três; 2016 com quatro; 2017 com dois; 2018 com dois; 2019 com dois. Contou com a participação de mais três docentes por períodos variados e atualmente conta com 2 docentes. Portanto, foram em torno de 65 acadêmicos (alguns repetiram a atividade nos anos subsequentes) que passaram pelo projeto em 18 anos de atividades ininterruptas. Foram publicados quatro artigos; três resumos expandidos; dois trabalhos completos em anais; 21 participações em congressos e cinco monografias. Há quem já chegou a doutorar-se, alguns outros ao nível de mestrado, ambos buscando a carreira acadêmica. Outros seguem com as atividades profissionais, poucos deixaram a profissão, mas todos informalmente reconhecem a diferença que o projeto exerceu em suas formações.

\section{Projeto Unioeste Runners}

Com início em agosto de 2016, o projeto Unioeste Runners é coordenado desde então pelo Prof. Dr. Ricardo Brandt. Seu objetivo é atender a população de Marechal Cândido Rondon e Região. Tem como objetivo promover a prática de corrida de rua para jovens, adultos e idosos. As atividades de corrida de rua são realizadas no complexo poliesportivo da Unioeste, duas vezes na semana, com duração de uma hora de atividades. As atividades são prescritas levando em conta as capacidades físicas dos participantes e para tal, são realizados testes e acompanhamentos das capacidades de forma sistemática.

A primeira turma de participantes contou com apenas 26 pessoas, que acreditaram que a corrida poderia melhorar sua qualidade de vida e saúde. Ao longo dos anos, a quantidade de participantes foi aumentando até chegar a mais de 130 participantes em março de 2019.

Este projeto recebe suporte de disciplinas da graduação, como anatomia, fisiologia do exercício, medidas e avaliação, cineantropometria e treinamento esportivo, psicologia do esporte, entre outras. Desta forma conseguimos proporcionar aos discentes uma formação completa, de aplicação prática dos conhecimentos apreendidos em sala de aula.

Já passaram por esse projeto alunos vinculados a bolsas de iniciação científica, com projetos de pesquisa que contribuíram de forma efetiva na produção de conhecimento relacionado a corrida de rua e variáveis que influenciam de forma direta na performance esportiva ou tem relação com a qualidade de vida e saúde. Entre os trabalhos citamos "Treinar corrida de rua melhora estados de humor e qualidade do sono" e "Efeito de um programa de treinamento de 12 semanas sobre a aptidão aeróbica e desempenho neuromuscular de praticantes de corrida de rua". Além de vinculados a bolsas de iniciação 
científica foram trabalhos de conclusão de curso.

Com as informações coletadas neste projeto de extensão, foi possível a participação de alunos, com apresentação de trabalhos em Semanas Acadêmicas, Evento Científicos e Seminário de Extensão da Unioeste.

No ano de 2019, em parceria com docentes da Universidade Estadual de Londrina (UEL), está sendo realizada uma pesquisa com os participantes do Unioeste Runners, vinculada a uma tese de doutorado, e com a Universidade do Estado de Santa Catarina (UDESC), vinculada a uma dissertação de mestrado.

\section{Projeto Futuro do Judô}

O Projeto de extensão de Judô do Curso de Educação Física da Unioeste iniciou suas atividades em março de 1998. No início este projeto tinha a duração de dois anos e a cada período era necessária apresentar um novo projeto com um nome diferente. Entretanto, a base da proposta e os objetivos do projeto sempre foram os mesmos, tendo a seguinte sequência: Judô para crianças carentes (1998/1999), Projeto de Judô da Unioeste (2000/2001), Venha praticar Judô com a gente (2002/2003). No ano de 2004 este projeto foi transformado em permanente e desde então passou a se chamar Projeto Futuro do Judô: iniciação e alto nível através do esporte social.

Este projeto desenvolvido há mais de 22 anos possui o objetivo de oferecer aulas de judô para crianças, adolescentes e jovens do município de Marechal Cândido Rondon, matriculados em colégios públicos do município, além de acadêmicos, filhos de professores e colaboradores da Unioeste. Anualmente são convidadas a participar deste projeto todas as instituições de ensino públicas de nosso município que indicam aproximadamente 100 alunos a cada ano. Estes são divididos em três turmas sendo atendidos três vezes por semana com uma hora de treino por dia. Conforme a evolução, os atletas que passam a ser de alto rendimento passam a treinar cinco vezes por semana com duas horas de treinos diários.

O projeto de judô sempre oportunizou bolsas de extensão para acadêmicos e anualmente temos dois ou três monitores no projeto que passam por treinamento e padronização. Estes acadêmicos necessitam e colocam em prática diversos conhecimentos da área de Educação Física como: treinamento esportivo, iniciação esportiva, medidas e avaliação, psicologia do esporte, anatomia, fisiologia, crescimento e desenvolvimento, lutas, dentre outros.

Para as turmas de iniciação ao judô são desenvolvidos: fundamentos básicos e específicos do judô; orientações e conscientização sobre disciplina, higiene, saúde, educação e cidadania dentre outros; e, regras e condutas do Judoca, competitivo e social.

Para as turmas de nível intermediário proporcionamos: revisão e aperfeiçoamento das atividades desenvolvidas na iniciação; conhecimentos sobre histórico, desenvolvimento e filosofia do Judô; iniciação e aperfeiçoamento de técnicas intermediárias; e, participação em competições oficiais e amistosas regionais.

Para as turmas de nível avançado: aperfeiçoamento das técnicas e fundamentos avançados e específicos do judô; estu- do avançado da história e filosofia do judô; análise, discussão e orientações de combates de alto nível; e, participações em competições estaduais, nacionais e internacionais, quando as classificações são obtidas.

Desde o princípio sempre trabalhamos com populações especiais, como portadores de deficiência, adolescentes infratores, crianças hiperativas, etc. Atualmente temos o destaque no judô paralímpico com um aluno deficiente visual total, Gustavo Alberto Ohse Hanke. Este atleta, no ano de 2018 sagrou-se Campeão Paranaense, Campeão Brasileiro e Campeão do Grand Prix Infraero de Judô para Deficientes Visuais. Em 2019, sagrou-se Campeão do Torneio Nacional Antônio Tenório da Silva e venceu pela segunda vez o Grand Prix Infraero de Judô para Deficientes Visuais. Atualmente, Gustavo, é acompanhado e orientado pelos professores Jean Carlo Arndt e Gabriela Simone Harnisch, egressos do Curso de Educação Física da Unioeste e colaboradores do projeto.

Duas vezes por ano, todos os alunos do projeto passaram por avaliações antropométricas e de aptidão física visando o acompanhamento da evolução dos mesmos. Estes dados também são utilizados para a publicação de estudos que são apresentados por nossos acadêmicos monitores em congressos ou publicados em revistas científicas.

Destaca-se que anualmente participamos do Seminário de Extensão Universitária da Unioeste, apresentando os resultados do projeto e já fomos selecionados algumas vezes e participamos do SEUR - Seminário de Extensão da Região Sul. Em 2016, com o nosso egresso Vitor Henrique Vassoler, tivemos a grata satisfação de receber o Destaque de Menção Honrosa no I Encontro Anual de Iniciação Científica, Tecnólógica e Inovação (EAICTI), da Unioeste.

Os alunos participantes do projeto também têm a oportunidade de realizar avaliações para mudança de faixas, que são as graduações no judô. Desde o início já formamos diversos alunos faixas Pretas e vários destes cursaram Educação Física e hoje atuam, ministrando aulas de judô em diversas cidades de nossa região.

O projeto, desde o seu início possui importantes parcerias, com: a) Associação Fujiyama de Judô e Federação Paranaense de Judô que proporcionam a mudança oficial de faixas e a participação em eventos oficiais; b) Colégio Luterano Rui Barbosa que acolhe as turmas de alto rendimento para os seus treinamentos, além de oportunizar bolsas de estudos para atletas destaques; c) Secretaria Municipal de Esportes e Lazer de Marechal Cândido Rondon que auxilia financeiramente com as anuidades de filiação de atletas de alto rendimento e a participação em competições oficiais; e, d) Empresas do município que auxiliam na aquisição dos judoguis, que são as roupas para a pratica do judô.

\section{CONCLUSÃO}

Entre as competências necessárias à formação do profissional em Educação Física, evidencia-se a importância da participação em projetos de extensão no processo de formação universitária, ampliando as possibilidades de aprendizado permitindo vivencias que farão diferença na vida profissional. 


\section{REFERÊNCIAS}

ANTUNES, A. C. Influência da Resolução 03/87 para o atual processo de preparação profissional em Educação Física. Lecturas, Educación Física y Deportes, Revista Digital, Buenos Aires, v. 4, n. 138, 2009. Disponível em: <https://www.efdeportes.com/efd138/resolucao-03-87-em-educacaofisica.htm>. Acessado em: 25 julho de 2019.

BRASIL. Ministério da Educação. Currículo Mínimo de Educação Física: Resolução n.ㅇ 03, de 16 de junho de 1987, do Conselho Federal de Educação. Brasília, 1987. Brasília: Documenta, no. 319, jul/87, p. 173-4. Disponível em: <https://crefrs.org.br/legislacao/pdf/resol cfe 31987. pdf>. Acessado em: 25 julho de 2019.

BRASIL. Lei № 10.741, de 1ำ de outubro de 2003. Dispõe sobre o estatuto do idoso e dá outras providências. Disponível em: <http://www. planalto. gov.br/ccivil 03/leis/2003/l10.741.htm>. Acessado em: 26 julho de2019.

BRASIL. Lei № 9696/98, de 1 de setembro de 1998. Dispõe sobre a regulamentação da Profissão de Educação Física e cria os respectivos Conselho Federal e Conselhos Regionais de Educação Física. Disponível em: <http://www.planalto.gov.br/ccivil 03/leis/I9696.htm>. Acessado em: 26 julho de 2019.

MELO, V. A. A educação física e o estado novo (1937-1945): a escola nacional de educação física e desportos. Lecturas, Educación Física y Deportes, Revista Digital, Buenos Aires, v. 12, n. 115, 2007. Disponível em: <https://www.efdeportes.com/efd115/a-educacao-fisica-e-o-estadonovo.htm>. Acessado em: 25 de julho de 2019.

SOUZA NETO, S.; ALEGRE, A. N.; HUNGER, D.; PEREIRA, J. M. A formação do profissional de educação física no Brasil: uma história sob a perspectiva da legislação federal no século XX. Revista Brasileira de Ciências do Esporte, Campinas, v. 25, n. 2, p. 113-28, 2004.

UNIOESTE. Conselho de Ensino Pesquisa e Extensão. Resolução № 102/2016-CEPE, de 30 de junho de 2016. Aprova o regulamento de elaboração e alteração do projeto político pedagógico de curso de graduação da Unioeste. Disponível em: <https://midas.unioeste.br/sgav/ arqVrtConteudo/download?arqCntCodigo=8781>. Acessado em: 26 de julho de 2019.

UNIOESTE. Conselho de Ensino Pesquisa e Extensão. Resolução № 253/2018-CEPE, de 6 de dezembro de 2018. Altera o Projeto PolíticoPedagógico do Curso de Educação Física - Bacharelado, do campus de Marechal Cândido Rondon. Disponível em: <https://midas.unioeste.br/ sgav/arqVrtConteudo/download?arqCntCodigo=9925>. Acessado em: 26 de julho de 2019

\section{AGRADECIMENTOS}

Os autores agradecem aos alunos do Curso de Educação Física que se dedicaram e se dedicam como monitores e aos diversos parceiros dos projetos que sempre possibilitam a continuidade dos mesmos.

\section{ORCID E E-MAIL DOS AUTORES}

Ricardo Brandt (Autor Correspondente) ORCID: 0000-0001-6018-0347.

E-mail: ricabrandt@gmail.com

Alberto Saturno Madureira

ORCID: 0000-0003-4639-5274.

E-mail: albertosmadureira@gmail.com

Edilson Hobod

ORCID: 0000-0003-4181-6690.

E-mail: Edilson.Hobold@unioeste.br 